\title{
Cystic echinococcosis in Lombardy: epidemiological aspects and spatial analysis
}

\author{
M. T. MANFREDI, A. R. DI CERBO, S. ZANZANI
}

\begin{abstract}
Department of Veterinary Science and Public Health, Veterinary Faculty, University of Milan, Italy, E-mail: mariateresa.manfredi@unimi.it
\end{abstract}

\begin{abstract}
Summary
A descriptive spatial analysis on the spreading of cattle cystic echinococcosis in non-endemic areas of Italy (Lombardy) was performed and the presence of clusters of hydatid disease in the studied area were evaluated. Positive cattle were from 285 out of 5708 farms (4.99\%) with significant differences among the provinces considered. Infection with Echinococcus granulosus was detected in 321 out of 112,521 dairy cattle $(P=0.29 \%)$. CE-positive farms were distributed among 195 of the 812 municipalities included in the study $(24.01 \%)$ located in the central and south-eastern part of the region. By SaTScan, four significant clusters of infection were identified; they included 4-241 cattle farms and $4-24$ positive animals. The most likely spatial cluster of 17 observed cases in 241 farms was located in the north-eastern part of Lombardy. SaTScan analysis suggest that a geographical surveillance in the area of the positive clusters occur is for and that's could be very useful to public health service to monitoring this zoonotic disease.
\end{abstract}

Keywords: cattle; Echinococcus granulosus; Italy; spatial analysis; cluster

\section{Introduction}

Spatial data analysis has been reckoned to be an important tool in providing additional insight within epidemiological cause-effect relationships (Pfeiffer, 1996). So far, a traditional approach has been mainly applied to describe the distribution pattern of cystic echinococcosis (CE), and only a few epidemiological studies considered spatial distribution of CE using a GIS-based approach. For instance, Barnes et al. (2007) applied a geographic information system to study E. granulosus infection clustering in Australia. Cringoli et al. (2007) georeferenced cattle farms to study spatial distribution of cystic echinococcosis in Campania region (southern Italy).
On the other hand, many studies adopting GIS applications were carried out on epidemiology of the alveolar echinococcosis (caused by E. multilocularis) in Europe and Asia (i.e. Tackmann et al., 1998; Staubach et al., 2001; Conraths et al., 2003; Danson et al., 2003 and 2006; Bercke, 2004; Deplazes et al., 2004; Pleydell et al., 2004; Duscher et al., 2006; Kamiya et al., 2007).

Within spatial analysis, spatial scan statistic is particularly suitable for geographical disease surveillance. Spatial scan statistics based on the likelihood ratio test are widely used for detecting a gathering of cases with unusually high or low rates of outcome variables in a specific area or geographical clusters (Jung et al., 2007). That is, clustering occurs if a disease is present in an area more frequently than expected. Under the null hypothesis of no clustering (i.e. random distribution of event cases) the probability of falsely detecting a cluster of points is equal to a specified significance level (Robinson, 2000). Methodological research on disease cluster techniques has developed in the last years (Jacquez, 2000). Scan statistics are used to detect and evaluate clusters in temporal, spatial or space-time settings. Disease mapping and clustering are important tools in modern epidemiology to study distribution of parasitic infections from a spatial (geographical) point of view. They allow both a descriptive analysis on the spreading of a disease and an evaluation of the disease risk factors.

Cystic echinococcosis is a matter of significant concern for public health in the Mediterranean basin. Annual incidences of hospital cases of human CE vary between 1 and 8 per 100,000 (Eckert and Deplazes, 2004). High endemicity of this parasite depends on extensive sheep farming and its presence also coincides with high prevalence of human cystic echinococcosis. As to Italy, the disease is endemic and most prevalent in the southern regions and in Sardinia and Sicily islands (Garippa et al., 2004). Few epidemiological studies on CE in animals were carried out in the country, and most of them investigated epidemio- 
logical patterns in the endemic regions of central and southern Italy (Capuano et al., 2006; Scala et al., 2006; Busi et al., 2007; Casulli et al., 2008; Rinaldi et al., 2008; Varcasia et al., 2011). Previous studies at abattoirs in northern Italy showed prevalence values below $1 \%$ in both sheep and cattle (Garippa et al., 2004; Manfredi et al., 2011). No studies using GIS are available for CE in nonendemic areas like Lombardy region. Given that cystic echinococcosis is strictly related to zootechnical production and that Lombardy is the most populated northern area with the largest share of land allocated to agricultural and zootechnical uses, investigating spatial distribution of echinococcosis within its boundaries would be of particular interest.

In this perspective, our researches dealt with the intermediate hosts of CE, as livestock are, by investigating $\mathrm{CE}$ cases in Lombard cattle farms and considering their implications to humans.

Specifically, the aims of this study were: i) to perform a descriptive spatial analysis on the spreading of this zoonotic disease by considering the largest slaughterhouse in Italy; ii) to evaluate the presence of clusters of hydatid disease in the studied area, /when given.

\section{Materials and methods}

\section{Study area}

The survey was carried out between June 2005 and June 2006 in Lombardy, a region of northern Italy (Latitude: $45^{\circ} 40^{\prime} \mathrm{N}$; Longitude: $9^{\circ} 30^{\prime}$ E) geographically characterised by mountains $(40.5 \%)$, hilly areas $(12.5 \%)$, and the vast Po plain $(47 \%)$. Out of its $23,859 \mathrm{~km}^{2}$ surface, $46.7 \%$ is allocated to agriculture, $19.2 \%$ is covered by woodland, $13.2 \%$ is uncultivated or used as pasture areas, and $8 \%$ is occupied by buildings and infrastructures. Its rural territory is generally associated with agricultural and zootechnical activities, including over $1,484,991$ cattle $(37.8 \%$ of the total amount of cattle bred in northern Italy), 105,759 sheep and 57,705 goats bred in farms (Data ISTAT, year 2010).

Lombardy is the most densely populated Italian region, and counts $9,917,714$ residents $(16.1 \%$ of the Italian population; ISTAT, year 2011) at a density of 416 inhabi$\operatorname{tants} / \mathrm{km}^{2}$.

A study investigated the presence of the cyst of E. granulosus in cattle from the largest slaughterhouse in Italy (INALCA S.p.A., Lodi, Lombardy). On the whole, 215,559 animals originating from all Italian regions were slaughtered at the abattoir in 2004. Out of which, a total of 112,521 cattle from 5708 farms were selected, considering only cattle born or housed in Lombardy for more than two years. Hydatid cysts were removed from parasitized organs during routine post-mortem veterinary controls, records were kept of the number, external diameter and viability of the hydatid cysts. Hydatid cysts were ranked as fertile, sterile, cysts with necrosis and calcified cysts. An animal was considered infected even if only one of these cysts was present. Data were also collected on the breed, sex and age of cattle.
Geographic Information System integration and spatial analysis

A geographical information system (GIS) was established to cover an area within the administrative boundaries (at provincial and municipal level) of Lombardy region (Dati Geografici di Sintesi of Lombardy Region, vers. 1.2, 2003). All farms where cattle slaughtered at the INALCA abattoir originated from, i.e. 2672 sheep- and 3299 goatfarms located in the study area, were geo-referenced and spatial distribution was investigated.

Thematic layers of land coverage and altitude were imported in the GIS. Both elevation above sea level (with a precision of $100 \mathrm{~m}$ ) and the corresponding code of land use were assigned to each farm location using spatial join operations.

To investigate the spatial distribution of CE-infection cases in cattle and to identify significant spatial clusters, if any, the local indicators of spatial association (LISA) and the software SaTScan vers. 7.0 (Information Management Services Inc., Silver Spring, MD, USA), were used. The LISA indicate the presence or absence of significant spatial clusters or outliers for each location by calculating local Moran's I for each spatial unit and evaluating the statistical significance for each $\mathrm{I}_{\mathrm{i}}$. Negative (positive) values of Moran's I indicate negative (positive) spatial autocorrelation. Values range from -1 (indicating perfect dispersion) to +1 (perfect correlation) (Anselin, 1995). The free download GeoDa package used for exploratory spatial analysis was employed. The SaTScan, a free software developed by M. Kulldorf (see http://www.satscan.org/), permits to detect spatial or spacetime disease clusters and to evaluate their statistical relevance. A detailed explanation on the different models that can be applied to data analysis is reported in Kulldorff (1997), Kulldorf et al. (2005, 2006 and 2007), and Jung et al. (2007). This method takes into account the uneven spatial geographic distribution of cases and population densities. The geographic scan statistic imposes a geographic circular window to perform purely spatial analysis of varying size on the map surface and creates an infinite number of distinct geographic circles with different sets of neighboring data locations within them. A cattle farm was considered to be our analysis unit. Thus, any farm proving one or more cases was named as a case farm in opposition to a non-case farm where no case/s occurred. The analysis also included a coordinate file showing the geographical coordinates of all locations of the studied farms. For any geographic position of the farms, the radius varied continuously from zero to a previously user-defined maximum. In this study, the maximum spatial cluster size was specified as $50 \%$ of the cattle population. The distribution and $p$-value of the most likely (primary) and other (secondary) clusters were determined by performing Monte Carlo replications (999) of the data set, using the Poisson model, adjusted for farm size, as it is particularly indicated for purely spatial analysis (Kulldorff, 1997). The test of significance of the identified clusters is based on a likelihood ratio test. The most likely cluster is the area associated with the maximum value of the likelihood ratio test statistic. 
Further, measuring distance from risk factors is a capability often used in spatial analyses. In this study, dogs living in sheep and goat farms were considered to be risk factors for the transmission of E. granulosus infections in cattle farms. Thus, linear distances from cattle farms and both sheep and goat farms were calculated.

\section{Results}

Positive cattle were from 285 out of 5708 farms (4.99\%, $95 \%$ CI: $4.45 \%-5.59 \%$ ) with significant differences among the provinces considered (Kruskall Wallis Test: $\chi^{2}$ : $44.95, p<0.001)$. Infection with E. granulosus was detected in 321 out of 112,521 dairy cattle $(\mathrm{P}=0.29 \% ; 95 \%$ CI: $0.26 \%-0.32 \%$ ) (Table 1 ).

The rate of infection, considering only positive farms, was $2.86 \%$ (95\% CI: $2.57 \%-3.18 \%$ ) on a total number of 11,222 slaughtered cattle. Geographically, CE-positive farms were mainly distributed in the central and southeastern part of the region, that is the Po Plain (Fig. 1) and were distributed among 195 of the 812 municipalities included in this study $(24.01 \%)$, with a range of $1-6$ posi-

\section{Legend}
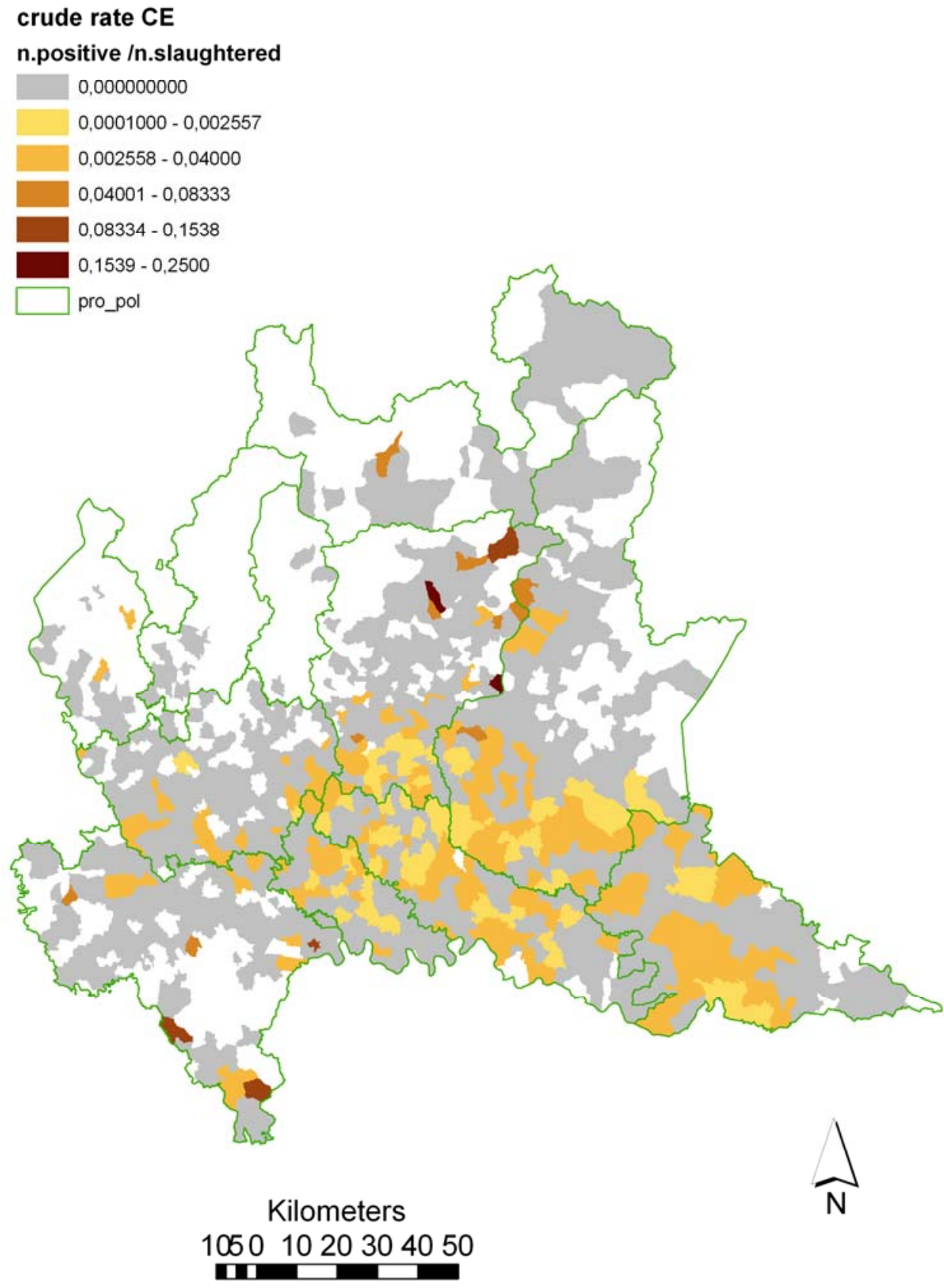
Table 1. CE infection in cattle raised in Lombard provinces. (CI: confidence interval)

\begin{tabular}{ccc}
\hline $\begin{array}{c}\text { Province } \\
\text { (n. farms) }\end{array}$ & $\begin{array}{c}\text { Farm positivity } \\
(\mathbf{\%} ; \mathbf{9 5} \% \mathbf{C I})\end{array}$ & $\begin{array}{c}\text { Crude rate } \\
\text { per 100,000 } \\
\text { slaughtered cattle } \\
\mathbf{( \% ;} \mathbf{9 5 \%} \% \mathbf{C})\end{array}$ \\
\hline BG (149) & $0.37(0.28-0.49)$ & $373(272-474)$ \\
BS (145) & $0.33(0.27-0.40)$ & $329(266-391)$ \\
CR (111) & $0.22(0.17-0.29)$ & $216(161-271)$ \\
LO (61) & $0.22(0.15-0.32)$ & $217(138-296)$ \\
MI (116) & $0.30(0.20-0.44)$ & $302(190-414)$ \\
MN (64) & $0.24(0.16-0.35)$ & $245(156-334)$ \\
PV (90) & $0.49(0.29-0.83)$ & $489(241-736)$ \\
SO (27) & $0.21(0.01-1.34)$ & 207 \\
VA (43) & $0.25(0.04-1.01)$ & 251 \\
TOT & $0.29(0.26-0.32)$ & $285(254-316)$ \\
\hline
\end{tabular}

tive farms (mean $\pm \mathrm{SD}: 1.46 \pm 0.88)$ and $1-11$ positive slaughtered heads (mean $\pm \mathrm{SD}: 1.65 \pm 1.28$ ) per municipality. Almost all of these farms $(95.4 \%)$ were located at altitudes below $500 \mathrm{~m}$ a.s.1. (min-max: 100 - $1300 \mathrm{~m}$ a.s.1.; median \pm SD: $100.0 \pm 172.4 \mathrm{~m}$ a.s.1.).

The surroundings to the farms were included in the map. The most frequent land category $(78.9 \%)$ was represented by agricultural areas, while a rather significant percentage of farms was related to urban or suburban areas (14.7\%) or other land typologies, such as meadow or pasture land $(3.8 \%)$ and deciduous forest $(1.8 \%)$. No statistically significant difference between farms positive or negative to $\mathrm{CE}$ was found as to land coverage (U Mann-Whitney test: $\left.\chi^{2}=48311.5 ; \mathrm{p}>0.05\right)$.

By local spatial autocorrelation analysis based on the Local Moran Univariate LISA statistics a choropleth map were produced showing a clustering of similar values: very high percentage of $\mathrm{CE}$ infected farms were where other $\mathrm{CE}$ infected farms were located, which are shown in red. In contrast, low percentage of CE infected farms was where there was other low percentage of $\mathrm{CE}$ infected farms, indicated in blue (Fig. 2). Those results were confirmed by the Moran's I value of 0.4809 , which indicates a strong positive autocorrelation. Using SaTScan, four significant clusters of infection were identified (Table 2). On the whole, they included $4-241$ cattle farms (mean(SD) $=143$ \pm 97.1, median: 154) and $4-24$ positive animals
$($ mean $(\mathrm{SD})=14.25 \pm 8.42$, median: 14.5$)$.

The most likely spatial cluster (primary cluster) of $17 \mathrm{ob}-$ served cases in 241 farms (compared with an expected 0.45 of positive cases), with a radius of $20.71 \mathrm{~km}$, was located in the north-eastern part of Lombardy. Secondary clusters were positioned in the southern part of Brescia province (cluster 2), in the Oltrepò Pavese (Cluster 3), and between Bergamo and Milano provinces (cluster 4) (Fig. 3).

Linear distance between cattle and small ruminants farms was calculated, since sheep and goat farms are considered to be among the major risk factors of bovine cystic echinococcosis. No significant differences between positive and negative farms were found either for sheep or for goat farms (Table 3).

A graphic display of human CE rate at provincial level is shown in Figure 4 (Manfredi et al., 2011).

\section{Discussion}

Data from this survey indicated that animal CE is hypoendemic in Lombardy and that the presence of an autochthonous cycle of E. granulosus may predominantly be due to the sheep-dog cycle, as it occurs in the Italian regions endemic for CE (Garippa et al., 2004). Prevalence seems to be sporadic in cattle, with $1-5$ positive animals per farm, according to previous findings at the slaughterhouse considered in our investigation (Fattori et al., 2000). However, the parasite was detected also in sheep from Lombardy and other adjacent regions, and in sheepdogs from farms located in the Prealpine areas (Manfredi et al., 2011). On the other hand, sheep and goat farms located in the Po Plain do not seem to have a significant role in the transmission of cystic echinococcosis, being characterized by an intensive management.

SaTScan approach provided clear evidence to the hypothesis suggesting that $\mathrm{CE}$ animal cases cluster geographically. In fact, significant spatial clusters of CE cases in cattle farms were identified in Bergamo and Brescia provinces together with a secondary cluster on the hills of Oltrepò Pavese. According to these results, the origin of cattle infection may reasonably be due to the contamination of these fields due to sheepdogs that follow transhumant flocks from alpine areas. In Lombardy transhumance is still practiced. Sheep are moved seasonally, from alpine pastures to lowlands in winter and vice versa in summer, and the main routes pass through Bergamo and Brescia provinces down to the Po Plain area. Geographically,

Table 2. Significant high rate CE spatial clusters in cattle in Lombardy

\begin{tabular}{cccccccc}
\hline Cluster & $\begin{array}{c}\text { Cluster } \\
\text { radius (km) }\end{array}$ & No. farms & $\begin{array}{c}\text { Observed } \\
\text { cases }\end{array}$ & $\begin{array}{c}\text { Expected } \\
\text { cases }\end{array}$ & Observed/Expected Relative risk p-value & poln \\
\hline 1 (primary) & 20.71 & 241 & 17 & 0.45 & 37.53 & 39.88 & 0.001 \\
2 & 8.57 & 199 & 24 & 4.66 & 5.15 & 5.54 & 0.001 \\
3 & 25.86 & 23 & 4 & 0.02 & 207.24 & 210.21 & 0.001 \\
4 & 5.58 & 109 & 12 & 1.50 & 8.00 & 8.31 & 0.001 \\
\hline
\end{tabular}




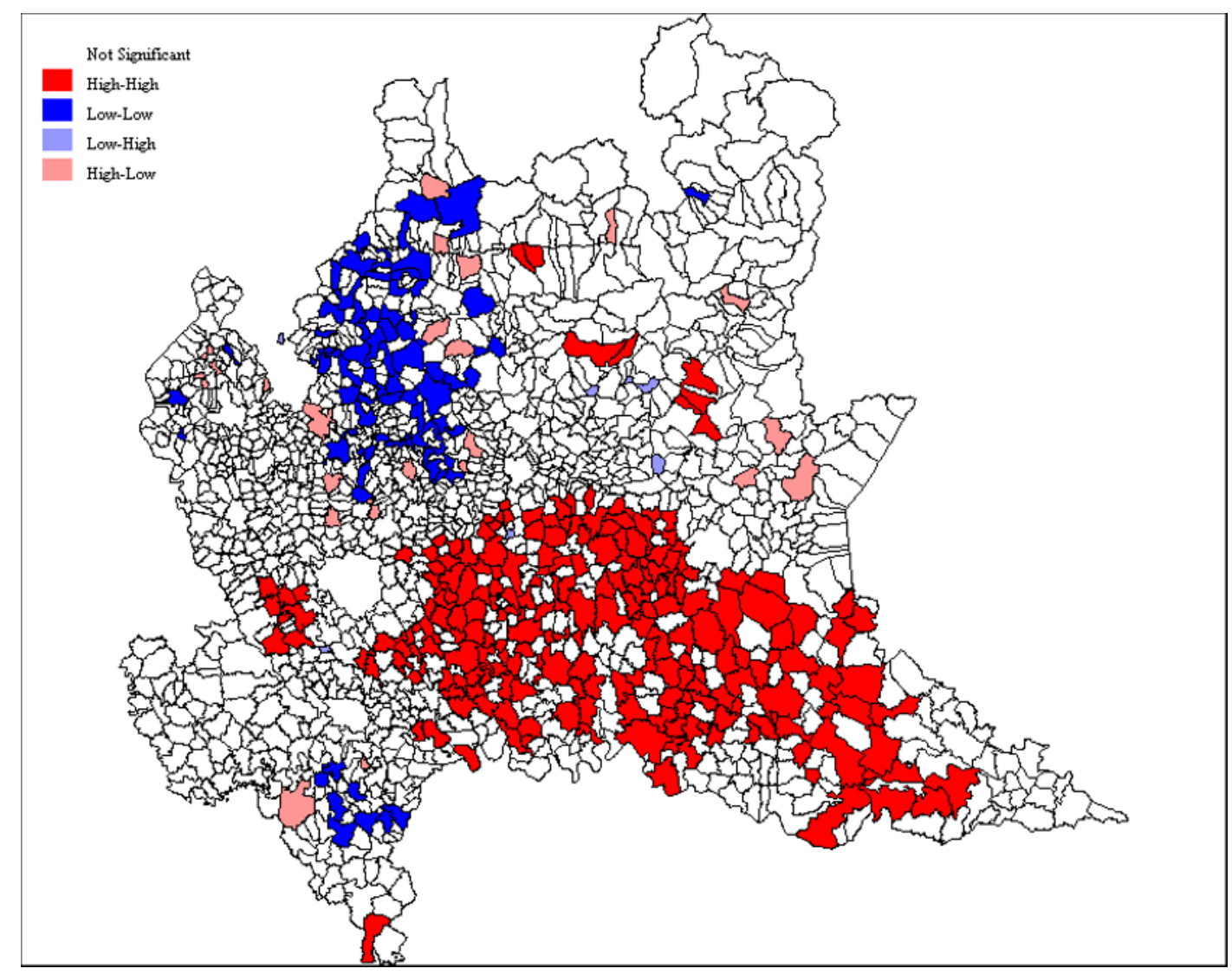

Fig. 2. Percentages of CE-infections in Lombard cattle farms using Local Indicators of Spatial Association (LISA)

farms with infected cattle appear to be located along the routes followed by transhumant sheep herds. CE infection may occur in sheepdogs or farm dogs by their ingestion of offal from dead sheep found near the farms or discharged there after home slaughtering of these ruminants; subsequently, the faeces of the dogs might affect the fields, thus causing the enclosed cattle to be infected by ingesting green fodder contaminated by taeniid eggs.

As to human cases, prevalence rates turned out to be higher than expected (Manfredi et al., 2011), given that Lombardy was traditionally considered a low-prevalence area for the infection and that even in animals CE prevalence resulted to be scarce. However, the highest number of cases per 100,000 inhabitants was observed in the provinces of Brescia and Cremona, just where CE in cattle showed the highest prevalence values.
Nevertheless, it was impossible to determine whether CE infection had occurred locally or originated via birth in other regions with higher endemicity.

Spatial scanning is a method to describe the geographic patterns of a disease and can provide useful additional information to data obtained by descriptive analysis. In particular, geographic areas in Lombardy where animal CE infection was either more likely or less likely to occur were identified by spatial analysis. This epidemiological approach resulted very useful to analyze the variation of $\mathrm{CE}$ infection for many possible small and large geographical groupings, and the differences resulting within the territory of Lombardy as to CE infection indicated a real animal and public health risk. According to some authors that emphasized the quite good ability of SaTScan in detecting differences when compared with other spatial statistic

Table 3. Distance to sheep and goat farms from cattle farms negative and positive to CE (distance values are expressed in kilometers)

\begin{tabular}{cccccccc}
\hline $\begin{array}{c}\text { Type of } \\
\text { farm }\end{array}$ & Cattle farms & Mean \pm SD & Min-max & $\begin{array}{c}\mathbf{2 5}^{\text {th }} \\
\text { percentile }\end{array}$ & $\begin{array}{c}\mathbf{5 0}^{\text {th }} \\
\text { percentile }\end{array}$ & $\begin{array}{c}\mathbf{7 5}^{\text {th }} \\
\text { percentile }\end{array}$ & p-value \\
\hline \multirow{2}{*}{ sheep } & negative & $3.77 \pm 2.78$ & $0-15.92$ & 1.66 & 3.23 & 5.23 & 0.121 \\
& positive & $4.03 \pm 2.89$ & $0-16.43$ & 1.79 & 3.53 & 5.81 & \\
\multirow{2}{*}{ goats } & negative & $2.74 \pm 2.05$ & $0-12.02$ & 1.26 & 2.29 & 3.73 & 0.058 \\
& positive & $2.95 \pm 2.06$ & $0-10.21$ & 1.36 & 2.57 & 4.01 & \\
\hline
\end{tabular}




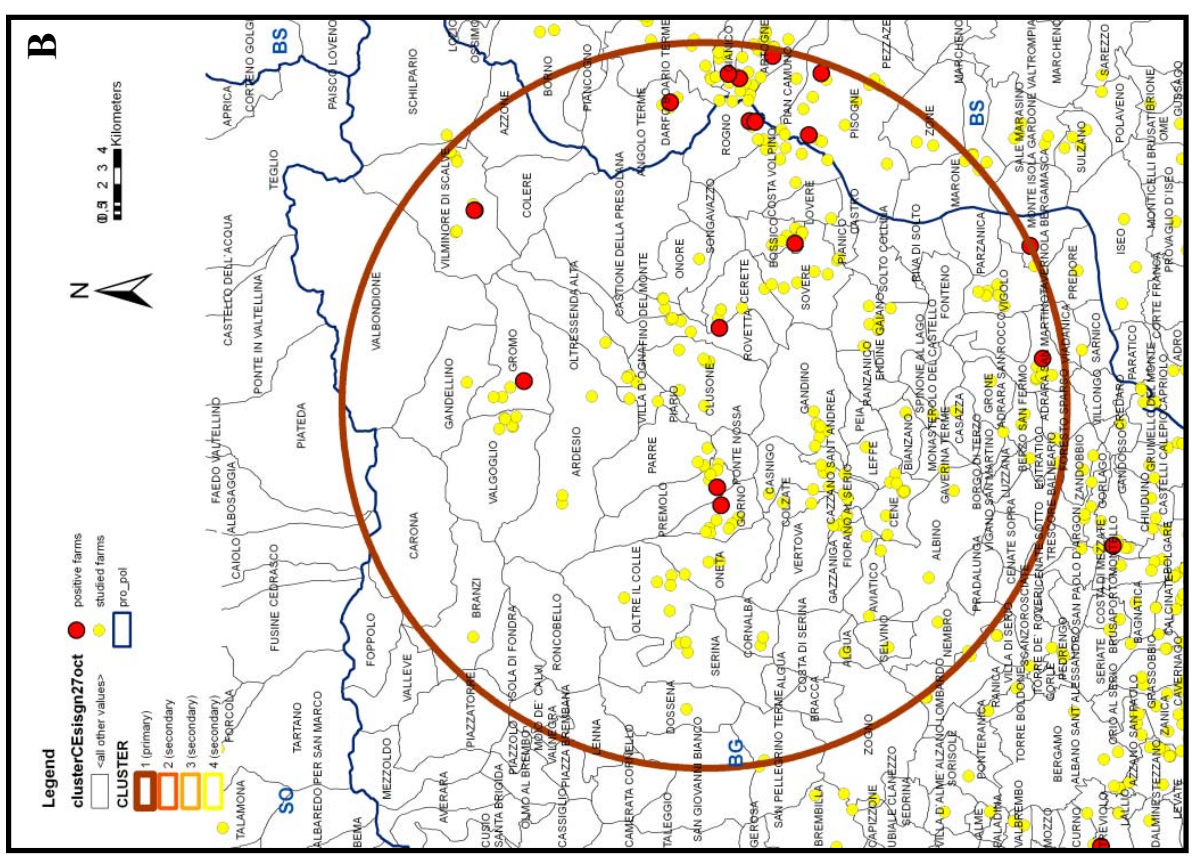

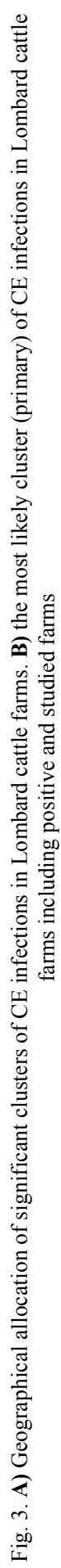




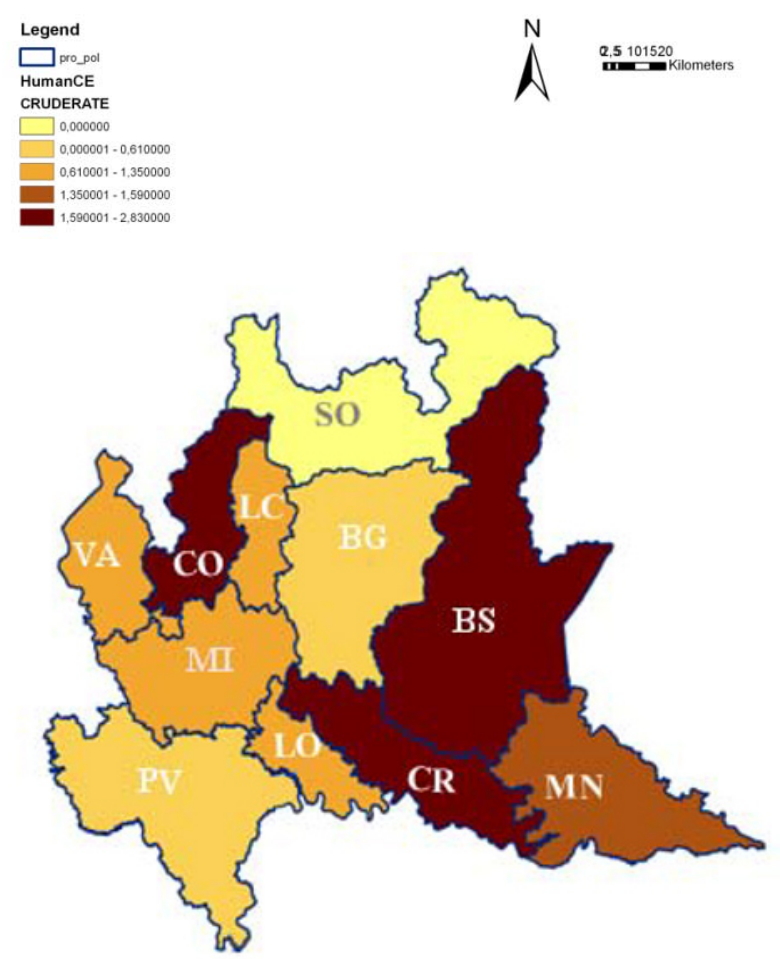

Fig. 4. Geographical allocation of human rate of CE-cases among Lombard provinces

tests, the results achieved by this method were consistent with a real epidemiological occurrence of CE cases rather than with the power of such statistical approach (Kulldorf et al., 2003). Furthermore, the congruence between the occurrence of CE in animals and humans can support that. Nevertheless, we consider that findings obtained in our study by SaTScan analysis can suggest need for a geographical surveillance where positive clusters occur and that monitoring this zoonotic disease would be very useful to public health service. As a matter of fact, the local Health System of Lombardy region sustained substantial costs associated with CE infection; anyway, high economic losses, amounting to $10 \%$ or even more (Kose and Sevimli, 2008, Manfredi et al., 2011) due to CE in cattle are caused by discarded organs and by decreased production.

\section{Acknowledgement}

We want to thank all veterinarians providing their practical support at INALCA slaughterhouse.

\section{References}

ANSELIN, L. (1995): Local indicators of spatial association - LISA. Geographical Analysis, 27: 93 - 115

Barnes, T. S., Morton, J. M., Coleman, G. T. (2007): Clustering of hydatid infection in macropodids. Int. J. Parasitol., 37: 943 - 952. DOI: 10.1016/j.ijpara.2007.01.014

BERKE, O. (2004): Exploratory disease mapping: kriging the spatial risk function from regional count data. Int. J. Health Geogr., 3: 18. DOI: 10.1186/1476-072X-3-18
Busi, M., ŠnÁbel, V., VArcasia, A., GaripPa, G., Perrone, V., De Liberato, C., D’amelio, S. (2007): Genetic variation within and between G1 and G3 genotypes of Echinococcus granulosus in Italy revealed by multilocus DNA sequencing. Vet. Parasitol., 30: 75 - 83. DOI: 10.1016/j.vetpar.2007.09.003

Capuano, F., Rinaldi, L., Maurelli, M. P., Perugini, A. G., Veneziano, V., Garippa, G., Genchi, C., Musella, V., CRINGOLI, G. (2006): Cystic echinococcosis in water buffaloes: epidemiological survey and molecular evidence of ovine (G1) and buffalo (G3) strains. Vet. Parasitol., 137: 262 - 268. DOI: 10.1016/j.vetpar.2006.01.016

Casulli, A., Manfredi, M. T., La Rosa, G., Di Cerbo, A. R., GenchI, C., PozIO, E. (2008): Echinococcus ortleppi and E. granulosus G1, G2 and G3 genotypes in Italian bovines. Vet. Parasitol. 155: 168 - 172. DOI: 10.1016/ j.vetpar.2008.04.004

Conraths, F. J., Staubach C., Tackmann, K. (2003): Statistics and sample design in epidemiological studies of Echinococcus multilocularis in fox populations. Acta Trop., 85: 183 - 189. DOI: 10.1016/S0001-706X(02)00215-2

Cringoli, G., Rinaldi, L., Musella, V., Veneziano, V., Maurelli, M. P., Di Pietro, F., Frisiello, M., Di PIETRO, S. (2007): Geo-referencing livestock farms as tool for studying cystic echinococcosis epidemiology in cattle and water buffaloes from southern Italy. Geospat. Health, 2(1): $105-111$

Danson, F. M., Giraudoux, P., Craig, P. S. (2006): Spatial modelling and ecology of Echinococcus multilocularis trasmission in China. Parasitol. Int., 55: S277 - S231. DOI: 10.1016/j.parint.2005.11.047

Danson, F. M., Graham, A. J., Pleydell, D. R., Campos-Ponce, M., Giraudoux, P., Craig, P. S. (2003): Multi-scale spatial analysis of human alveolar echinococcosis risk in China. Parasitology, 127: S133 - S141

DATA ISTAT (2010): Italian National Institute of Statistics. Retrieved from http//www.istat.it

Deplazes, P., Hegglin, D., Gloor, S., Romig, T. (2004): Wilderness in the city: the urbanization of Echinococcus multilocularis. Trends Parasitol., 20 (2): 77 - 84. DOI: 10.1016/j.pt.2003.11.011

Duscher, G., Pleydell, D., Prosl, H., JoAchim, A. (2006): Echinococcus multilocularis in Austrian foxes from 1991 until 2004. J. Vet. Med. B., 53: 138 - 144. DOI: 10.1111/j.1439-0450.2006.00930.x

ECKERT, J., DePlazeS, P. (2004): Biological, epidemiological, and clinical aspects of echinococcosis, a zoonosis of increasing concern. Clin. Microbiol. Rev., 17 (1): $107-$ 135. DOI: 10.1128/CMR.17.1.107-135.2004

Fattori, D., Biggioggero, S., Dordoni, E., Morici, R., Perri, M., Prandi, N., Tessuto, L. (2000): Epidemiologia nella filiera di macellazione più grande d'Europa. L'Osservatorio, 3 (2 aprile 2000): 8 - 9

Garippa, G., Battelli, G., Cringoli, G., Giangaspero, A., Giannetto, S., Manfredi, M. T. (2004): Aggiornamenti epidemiologici sull'echinococcosi animale in Italia. Parassitologia, 46: $37-38$

JunG, I., KulldorfF, M., KlASSEN, A. C. (2007): A spatial 
scan statistic for ordinal data. Statist. Med. 26: $1594-1607$ KAMIYA, M., LAGAPA, J. T., OKU, Y. (2007): Research on targeting sources of alveolar echinococcosis in Japan. Comp. Immunol. Microbiol. Infect. Dis., 30: 427 - 448. DOI: 10.1016/j.cimid.2007.05.004

Kose, M., Sevimli, S. K. (2008): Prevalence of cystic echinococcosis in slaughtered cattle in Afyonkarahisar. Turkiye Parazitol. Derg., 32 (1): 27 - 30

KulldorfF, M. (1997): A spatial scan statistic. Commun. Stat. Theory Methods, 26: 1481 - 1496

KulldorfF, M., HefFernan, R., HARTMAN, J., AssuncÃo, R., Mostashari, F. (2005): A space-time permutation scan statistic for the early detection of disease outbreaks. PLoS Med., 2: 216 - 224

Kulldorff, M., Huang, L. Pinckle, L., Duczmal, L. (2006): An elliptic spatial scan statistic. Statist. Med., 25: $3929-3943$

Kulldorff, M., Mostashari, F., Duczmal, L., Yih, W. K., Kleinman, K., Platt, R. (2007): Multivariate scan statistics for disease surveillance. Statist. Med., 26: $1824-$ 1833

Kulldorff, M., Tango, T., Park, P. J. (2003): Power comparisons for disease clustering tests. Comput. Stat. Data Anal., 42: 665 - 684. DOI: 10.1016/S01679473(02)00160-3

Manfredi, M. T., Di Cerbo, A. R., Zanzani, S. A., Moriggia, A., Fattori, D., Siboni, A., Bonazza, V., Filice, C., BRunetTi, E. (2011): Prevalence of echinococcosis in humans, livestock and dogs in northern Italy. Helminthologia, 48: 2: 59 - 66. DOI: 10.2478/s11687-011-0011-9 PFEIFFER, D. U. (1996): Issue related to handling of spatial data. In: McKenzIE, J. (Ed) Proceeding of the epidemiology and state veterinary programmes. New Zealand Veterinary Association/Australian Veterinary Association Second Pan Pacific Veterinary Conferences, June 23 - 28,
1996. Christchurch, New Zealand, 1996, pp. 83 - 105

Pleydell, D. R. J., Raoul, F., TourneuX, F., Danson, F. M., Graham, A. J., Craig, P. S., GiraudouX, P. (2004): Modelling the spatial distribution of Echinococcus multilocularis infection in foxes. Acta Trop., 91: 253 - 265. DOI: 10.1016/j.actatropica.2004.05.004

Rinaldi, L., Maurelli, M. P., Veneziano, V., Capuano, F., Perugini, A. G., Cringoli, G. (2008): The role of cattle in the epidemiology of Echinococcus granulosus in an endemic area of southern Italy. Parasitol. Res, 103: 175 179. DOI: $10.1007 / \mathrm{s} 00436-008-0948-\mathrm{x}$

RoBINSON, T. P. (2000): Spatial statistics and geographical information systems in epidemiology and public health. Adv. Parasitol., 47: 82 - 127. DOI: 10.1016/S0065308X(00)47007-7

Scala, A., Garippa, G., Varcasia, A., Tranquillo, V. M., GENCHI, C. (2006): Cystic echinococcosis in slaughtered sheep in Sardinia (Italy). Vet. Parasitol., 135: 33 38. DOI: 10.1016/j.vetpar.2005.08.006

Staubach, C., Thulke, H. H., Tackmann, K., HughJones, M., CONRATHS, F. J. (2001): Geographic information system-aided analysis of factors associated with the spatial distribution of Echinococcus multilocularis infections in foxes. Am. J. Trop. Med. Hyg., 65: 943 - 948

Tackmann, K., Loschner, U., Mix, H., Staubach, C., ThulKe, H. H., ConRATHS, K. J. (1998): Spatial distribution pattern of Echinococcus multilocularis (Leuckart 1863) (Cestoda: Cyclophillidea: Taenidae) among red foxes in an endemic focus in Brandenburg, Germany. Epidemiol. Infect., 120: 101 - 109. DOI: 10.1017/S0950268897008406 Varcasia, A., Tanda, B., Giobbe, M., Solinas, C., PiPia, A. P., Malgor, R., Carmona, C., Garippa, G., Scala, A. (2011): Cystic echinococcosis in Sardinia: Farmers' knowledge and dog infection in sheep farms. Vet. Parasitol., 181 (2 - 4): 335 - 340. DOI: 10.1016/j.vetpar.2011.05.006 